Nilai-Nilai Pendidikan Islam Dalam Al-Qur'an Dan Hadist

\title{
NILAI-NILAI PENDIDIKAN ISLAM DALAM AL-QUR'AN DAN HADIST
}

\author{
Ike Septianti \\ Devy Habibi Muhammad \\ Ari Susandi \\ Sekolah Tinggi Agama Islam Muhammadiyah Probolinggo \\ Email: ikeseptianti123@gmail.com
}

\begin{abstract}
The goal of this research is to find out what the Qur'an and hadith say about education and what ideals they include. This study intends to 1) learn the values of Islamic education found in the Qur'an and hadith, and 2) learn the cultivation of Islamic educational ideals contained in surah al-Hujurat. This study employs a content analysis technique to qualitative research. The tahlily approach was employed in this study. Data is evaluated utilizing tahliliy methods to study surah al-Hujurat and surat Al-baqarah connected to Islamic educational ideals, as well as analyze and interpret hadith, during the data gathering stage of library research. The findings of this research show that educational values in the Qur'an and hadith are the most important sources in the pedidikan of human character, where education is an effort to form a human being who practices karimah and is expected to become a more obedient, godly human being, with the main goal of bringing humans closer to Allah SW'T. Surah Al-Hujurat verses 11-12 and Surah Luqman verses 13-14 in the Qur'an contain Islamic educational values. Both letters are samples of a series of islamic educational ideals letters.
\end{abstract}

Keywords: Islamic Educational V alues, Quran, Hadith

\section{Abstrak}

Tujuan penelitian ini adalah menentukan nilai-nilai pendidikan di Al-Qur'an dan hadist, apa saja kandungannya. Penelitian ini diasari oleh rasa ingin tahu penulis, tentang apa saja isi Al-Qur'an dan hadist dengan tujuan mengetahui 1) apa saja isi dari Al-Qur'an dan Hadist yang berisi tentang nilai-nilai pendidikan 2) What is the meaning or content of Surah Al-Hujurat ayat 11-12 and Surah Luqman ayat 13-14? Penulis menggunakan jenis peneliian kualitatif dan menganalisa dari beberapa jurnal dan buku dalam penelitian ini. Serta, tidak lupa mengkaji dan memahami ayat Al-Qur'an dan hadist sebagai metode penelitian, yang dikenal dengan metode tahlily. Penulis memahami isi kandungan dalam Hadist atau sering disebut dengan teknik library reseach sebagai teknik dalam pengumpulan data-datanya, mengkaji surah Al-Hujurat, surah Luqman, dan memahami isi kandungan dalam Hadist or sering disebut dengan teknik Hasil penelitian ini adalah Nilai-nilai pendidikan dari Al-Qur'an, and hadist merupakan dasar yang memiliki kedudukan yang paling utama sebagai sumber dalam pedidikan karakter manusia, dimana pendidikan tersebut merupakan suatu upaya. Nilai-nilai pendidikan Islam dapat ditemukan dalam Surah Al-Hujurat ayat 1112 dan Surah Luqman ayat 13-14 Al-Qur'an. Masing-masing surah yang tercantum di atas adalah contoh dari salah satu surah yang berhubungan dengan nilai-nilai pendidikan Islam.

Kata Kunci : Nilai-nilai Pendidikan Islam, Al-Quran, Hadist

\section{PENDAHULUAN}

Pendidikan adalah proses mengubah perilaku dan etika seseorang untuk menuju kehidupan dan arah yang lebih baik. Tentu saja dapat digunakan dalam proses pembelajaran untuk menentukan tidak

\footnotetext{
${ }^{1}$ Soni Samsu Rizal, "Nilai-Nilai Pendidikan Islam Yang Terkandung Dalam Alquran Surat As-Sajdah Ayat 9 Relevansinya Dengan Pendidikan Pranatal," Tarbiyah Al-Aulad 1, no. 2 (2016): 16.

23| Falasifa, Vol. 12 Nomor 2 September 2021
} 
Ike Septianti

Dery Habibi Muhammad

Ari Susandi

hanya pola etika dan perilaku individu seperti apa yang dapat dihasilkan dari proses tersebut, yang juga tergantung pada norma-norma yang berlaku pada seseorang ${ }^{2}$

Pendidikan islam mempunyai prinsip pendidikan yang berladaskan ajaran serta nilai-nilai tentang islam. ${ }^{3}$ Oleh sebab itu hal dasar tersebut merupakan yang utama yang memiliki fungsi sebagai dasar penunjuk arah serta penuntuk kepada pendidikan islam. Disini landasan serta dasar ini merupakan acuan bagi pendidik dan juga peserta didik dengan tujuan mendapatkan pendidikan yang hakiki ${ }^{4}$.

Pendidikan islam merupakan suatu proses pembentukan akhlak mulia, pengembangkan nilai-nilai kemanusiaan, persusif serta halus, pendidikan islam harus berisi tentang nilai-nilai ketuhanan diman nilai-nilai tersebut berdasar pada Al-Qur'an serta Hadist ${ }^{5}$.

Penanaman etika salah satu dasar manusia sebagai proses mengatur hubungan antara manusia kepada Allah SWT, serta mengatur hubungan antara manusia dengan sesama ${ }^{6}$.

Pemberian pendidikan islam bertujuan memberikan perlindungan kepada anak-anak dimana mereka adalah para penerus bangsa dimasa depan, Pendidikan islam akan menjadi suatu benteng sosial yang kokoh yang akan menjaga generasi penerus bangsa dari ancaman kehidupan dimasa depan. Disini peran serta orang tua dalam mengasuh dan membimbing putra-putrinya merupakan kekuatan yang utama. Hal itu dikarenakan orang tua merupakan madrasah pertama bagi anak-anaknya dimana hal tersebut merupakan pondasi atau dasar pertama dan seterusnya, walaupun telah sering kita dengar bahwa orang tua adalah pendidik dalam keluarga sedangkan guru adalah pendidik di sekolah, ${ }^{7}$ serta tak lupa pula tokoh masyarakat yang juga berperan dalam pendidikan di masyarakat, akan tetapi peran orang tua tidak hanya terputus pada pendidikan anak di rumah saja, orang tua akan terus membimbing dan memberikan nasehat kepada anak-anaknya,ini merupakan sebuah bukti dari rasa tanggung jawab dari orang tua kepada keberhasilan pendidikan anak-anakya ${ }^{8}$.

Al-Qur'an adalah sumber pendidkan serta ilmu pengetahuan yang mendidik manusia dengan dengan bahasa yang lembut,balaqhah yang indah, sehingga Al-Qur'an mampu perubahan terhadap

\footnotetext{
${ }^{2}$ Ari Susandi, "Pendidikan Life Skills Dalam Penanaman Nilai-Nilai Agama Islam Di Sekolah Dasar," Al-Insyirob: Jurnal Studi Keislaman 6, no. 2 (2020): 95-111, https://doi.org/10.35309/alinsyiroh.v6i2.3867.

${ }^{3}$ Devy Habibi Muhammad, "Implementasi Pendidikan Humanisme Religiusitas Dalam," Edumaspul Jurnal Pendidikan 4, no. 2 (2020): 122-31.

4 Suheri Sahputra Rangkuti, "Suheri Sahputra Rangkuti : Nilai-Nilai Pendidikan Islam Dalam Tafsir Ayat Jihad ...," Jurnal Kependidikan Islam 4, no. 2 (2018): 184-201.

5 Abdul Wahab Syakhrani, "Memperkuat Eksistensi Pendidikan Islam Di Era 4.0," CBJIS : Cross-Border Journal of Islamic Studies 1, no. 2 (2019): 57-69, https://doi.org/10.37567/siln.v1i2.90.

${ }^{6}$ Muhammad Syamsi Harimulyo, Benny Prasetiya, and Devy Habibi Muhammad, "Nilai-Nilai Pendidikan Akhlak Dalam Kitab Risalatul Mu'awanah Dan Relevansinya," Jurnal Penelitian IPTEKS 6, no. 1 (2021): 72-89, https://doi.org/10.32528/ipteks.v6i1.5253.

${ }^{7}$ Ulil Hidayah, "Rekonstruksi Evaluasi Pendidikan Moral Menuju Harmoni Sosial," Jurnal Pedagogik 05, no. 01 (2018): 69-81, https://ejournal.unuja.ac.id/index.php/pedagogik\%0APermata_ulya@yahoo.co.id.

8 Alimul Muniroh, "Implementasi Nilai-Nilai Pendidikan Islam Dalam Surah As-Saffat Ayat 102," Darajat: Jurnal Pendidikan Agama Islam 1, no. 1 (2018): 1-15.
} 
pendidkan serta mampu mengajak para ilmuan agar ikut menggali, memahami, serta menggali apa saja yang terkandung didalamnya dengan tujuan agar manusia lebih dekat kepada Allah SWT ${ }^{9}$

Di dalam Al-Qur"an memiliki banyak kandungan yang isinya memuat bermacam-macam aspek kehidupan, salah satunya tentang kehidupan manusia, tidak ada penuntun serta dasar yang melebihi AlQur'an, yang didalamnya berisi bermacam-macam hikmah kehidupan, alam beserta isinya yang tidak akan pernah putus untuk selalu dipelajari serta dikaji1 ${ }^{10}$. Sudah suatu hal yang tidak dapat di pungkiri bahwa Al-Qur'an merupakan petunjuk bagi manusia, cara penyampaian yang variatif serta serta dikemas sedemikian rupa. Dimana didalamnya berisi, informasi, larangan,perintah serta telah dimodifikasi kedalam bentuk kisah yang mengandung pelajaran, disebut sebagai kisah-kisah Al-Qur'an ${ }^{11}$.

Dari beberapa uraian latar belakang diatas maka dapat permaslahan pada penelitian ini dapat drumuskan sebagai berikut: 1. Apa saja nilai-nilai yang ditemukan dalam Al-Qur'an dan hadits? 2. Tentang apa ayat 11-12 Surah Al-Hujurat?. dan tujuan dari penelitian ini adalah untuk mengetahui nilainilai pendidikan Islam yang terdapat dalam Al-Qur'an dan hadits. 2. Untuk mengetahui isi surat AlHujurat ayat 11 dan 12. 3. Untuk mengetahui apa isi surat Lukman ayat 13-14.

\section{PEMBAHASAN}

\section{Nilai-Nilai Pendidikan Dalam Al- Qur'an}

Sebagaimana diketahui, Al-Qur'an adalah pedoman bagi semua makhluk, dan Islam adalah agama yang sempurna, sehingga semua ajaran Islam, serta pendidikan karakter, memiliki logika. AlQur'an adalah dasar dari pendidikan karakter ${ }^{12}$ Dengan kata lain, semua asas lainnya selalu dikembalikan kepada Al-Qur'an, yang memuat semua hukum dan norma kehidupan, termasuk pendidikan. Al-Qur'an adalah pedoman dan acuan bagi kehidupan manusia, sebagai peta jalan menuju kehidupan yang lebih baik di dunia dan di akhirat. ${ }^{13}$.

Ketika datang ke sumber instruksional, Al-Qur'an berada di urutan teratas. Nilai-nilai yang ditemukan dalam Al-Qur'an harus selalu mengatur kegiatan dan proses pendidikan Islam. Karena mengandung beberapa aspek yang sangat baik untuk kemajuan pendidikan. ${ }^{14}$

\footnotetext{
${ }^{9}$ Rizal, "Nilai-Nilai Pendidikan Islam Yang Terkandung Dalam Alquran Surat As-Sajdah Ayat 9 Relevansinya Dengan Pendidikan Pranatal."

${ }^{10}$ Imanuddin Abil Fida, "Liberalisme Dalam Pendidikan Islam Di Perguruan Tinggi," Journal of Islamic Education I, no. 1 (2016): 56-70.

11 Muniroh, "Implementasi Nilai-Nilai Pendidikan Islam Dalam Surah As-Saffat Ayat 102."

${ }^{12}$ Muhammad, "Implementasi Pendidikan Humanisme Religiusitas Dalam."

13 Anggi Fitri, "Pendidikan Karakter Prespektif Al-Quran Hadits," TA'LIM : Jurnal Studi Pendidikan Islam Vol.1 No.2, no. 2 (2018): 38-67.

${ }^{14}$ M. Akmansyah, “Al-Quran Dan Al-Sunnah Sebagai Dasar Ideal Pendidikan Islam," Jurnal Pengembangan Masyarakat Islam 8 , no. 2 (2010): 127-42.

25| Falasifa, Vol. 12 Nomor 2 September 2021
} 
Ike Septianti

Devy Habibi Mubammad

Ari Susandi

Pendidikan disini merupakan bentuk upaya manusia untuk hidup lebih baik, di zaman saat ini pendikan memiliki peran penting dalam kehidupan terutama pendidikan islam, pendidikan islam ini merupakan dasar pembinaan akhlakul karimah pendidikan islam disini memiliki dasar ajaran agama islam yang rahmatal lil'alamin.dimana dasar utama pendidikan agama islam ini berdasar pada Al-Qur'an 15

Pendidikan agama Islam merupakan prioritas utama bagi semua orang termasuk peserta didik . Sehingga Pendidkan agama Islam diberikan dimulai sejak dini, seperti yang kita tahu bahwa menuntut ilmu dimulai dari lahir sampai akhir hayat tidak kan pernah ada putusnya ${ }^{16}$, ini merupakan suatu bukti bahwa pendidikan adalah hal utama yang mampu bembawa manusi menjadi manusia yang lebih baik ,oleh karenanya telah di lakukan tahapan -tahapan Pendidikan agama Islam yang diberikan kepada peserta didik disesuai dengan tingkatan jenjang pendidikannya, pendidikan agama islam juga harus sesuai dengan usia ${ }^{17}$

Secara umum, pendidikan Islam dapat diartikan sebagai ilmu pendidikan yang berbasis Islam. Sehingga, pendidikan Islam harus berlandaskan Al-Qur'an dan hadits Nabi. ${ }^{18}$.

Pendidikan agama Islam meliputi segala upaya untuk melestarikan fitrah manusia dan sumber daya manusia dengan tujuan keseluruhan membentuk insan Kamil yang sempurna menurut standar Islam. ${ }^{19}$.

Semua manusia dimotivasi oleh Al-Qur'an, yang menjadikan Al-Qur'an satu-satunya sumber arahan, memastikan bahwa manusia selalu berada di jalan yang konstruktif dan berguna untuk kehidupan di dunia ini dan selanjutnya. Akibatnya, Al-Qur'an mencakup semua aspek kebutuhan manusia. Hasilnya, ditemukan ayat-ayat Al-Qur'an yang membahas berbagai topik yang melengkapi berbagai aspek kehidupan manusia ${ }^{20}$.

\section{Nilai-Nilai Pendidikan Islam Dalam Al-Qur'an Surat Al-Hujurat Dan Surah Luqman}

\section{Nilai-nilai pendidikan dalam islam dalam surat Al-Hujurat}

Salah satu nilai utama dalam Al-Qur'an adalah pendidikan akhlak, yang dikodifikasikan dalam salah satu Surat, Surat Al-Hujurat, yang berisi perintah untuk tidak mencela orang lain. Karena orang

\footnotetext{
${ }^{15}$ Lilik Nur Kholidah, "Pola Integrasi Nilai-Nilai Keislaman Dalam Pembelajaran Pendidikan Agama Islam Pada Lembaga Pendidikan," At-Ta'dib 10, no. 2 (2015): 325-40.

${ }^{16}$ Susandi, "Pendidikan Life Skills Dalam Penanaman Nilai-Nilai Agama Islam Di Sekolah Dasar."

${ }^{17}$ Indah Soekmawati, "Nilai-Nilai Penting Pendidikan Islam Berbasis Al Quran Dan Sirah Nabi Dalam Peningkatan Kualitas Pengajaran," Jurnal Kependidikan 7, no. 2 (2019): 204-14, https:/ / doi.org/10.24090/jk.v7i2.3032.

${ }^{18}$ Hisam Ahyani Dian Permana, "Implementasi Pendidikan Islam Dan Pendidikan Multikultural Pada Peserta Didik," Dian Permana, Hisam Abyani Jurnal Tawadhu 4, no. 1 (2020): 1689-99.

19 Ade Imelda Frimayanti, "Implementasi Pendidikan Nilai Dalam Pendidikan Agama Islam," Al-Tadzkiyyah: Jurnal Pendidikan Islam 8, no. 2 (2017): 240.

${ }^{20}$ Suharnis, "Nilai-Nilai Pendidikan Islam Dalam Keluarga," Musawa 7, no. 1 (2015): 52-79.
} 
yang dihina mungkin lebih unggul dari orang yang dihina. Melakukan panggilan telepon yang berbahaya kepada orang-orang adalah melanggar hukum. Menyebarkan rumor tentang orang lain bukanlah ide yang baik. Surah Al-Hujurat ayat 11-12 menjelaskan perintah untuk meninggalkan Suudzan, mencaricari kesalahan orang lain, dan mengoceh tentangnya. ${ }^{21}$.

Jika Anda mencoba memahami Ayat 11, Anda akan melihat bahwa ayat itu masih mempromosikan pendidikan karakter dalam kaitannya dengan etika Muslim. Larangan mengolok-olok orang atau kelompok lain, bertindak seolah-olah mereka yang terbaik dan benar, dan tidak mengkritik diri sendiri, menyiratkan bahwa orang-orang beriman adalah satu tubuh, sama seperti ketika mereka mengkritik atau menghina orang lain, itu sama dengan menghina dan membuat menyenangkan diri mereka sendiri. Menyebut nama orang yang tidak disukai orang lain juga dapat diterima. Sikap seperti itu akan menimbulkan rasa hormat terhadap orang lain, serta rasa hormat terhadap sudut pandang orang lain. Jadi, orang-orang yang menolak untuk bertobat termasuk di antara orang-orang yang zalim, menurut kitab suci ini. Ayat ini mengandung nilai-nilai karakter orang yang suka mengolok-olok orang lain, dan pencela, yang suka mengkritik orang lain. ${ }^{22}$

Sedangkan ayat 12 memuat pendidikan karakter, karakter yang dimaksud adalah pantangan terhadap prasangka, mencari kekurangan orang lain, dan bergosip. Seseorang yang bergosip tentang orang lain, bahkan jika yang dia bicarakan adalah kebenaran (aib harus disembunyikan, tidak menyebar), sebanding dengan seseorang yang memakan bangkai saudaranya sendiri, bukankah itu menjijikkan? Prasangka (yang harus dimiliki agar berprasangka baik), tajassus, mencari kesalahan, fitnah, dan takwa adalah nilai karakter yang terkandung dalam bait ini ${ }^{23}$

\section{Nilai-nilai pendidikan islam dalam surat Luqman}

Al-Qur'an tidak hanya memuat nilai-nilai pendidikan Islam dalam Surah Al-Hujurat, tetapi juga dalam Surah Luqman, yang memiliki lebih banyak surat yang mendefinisikan pendidikan Islam. Dalam hal ini, Al-Qur'an juga mencakup konsep pendidikan, serta metode penyampaiannya ${ }^{24}$.

Di dalam Al-Qur'an, banyak ayat yang menyinggung tentang konsep pendidikan, salah satunya dalam surat Luqman, yang menawarkan pengajaran Luqman kepada putranya. Bait ini sarat akan nilai dan tata cara pendidikan yang ditanamkan Luqman kepada anak-anaknya (ahmad, 2018).

\footnotetext{
${ }^{21}$ Siti Ngaisah, "Nilai-Nilai Pendidikan Akhlak Dalam Surat ( Kajian Tafsir Al-Mishbah Karya Prof . Dr . M . Quraish Shihab ) Program Studi Pendidikan Agama Islam Institut Agama Islam Negeri” 13 (2018).

${ }^{22}$ S Zulkarnain and Kementerian Pemuda, "Pendidikan Karakter Dalam Al-Quran Surat Al-Hujurat" IX, no. 2 (2016): 13345.

23 Zulkarnain and Pemuda.

${ }^{24}$ Soekmawati, "Nilai-Nilai Penting Pendidikan Islam Berbasis Al Quran Dan Sirah Nabi Dalam Peningkatan Kualitas Pengajaran."

27| Falasifa, Vol. 12 Nomor 2 September 2021
} 
Ike Septianti

Devy Habibi Mubammad

Ari Susandi

Salah satu dari ayat menjelasakan tentan pendidikan yaitu ayat 14 yang artinya: “ dan kami perintahkan kepada manusia (agar berbuat baik)kepada kedua orang tuanya. Ibunya yang telah mengandungnya dalam keadaan lemah dan bertambah-tambah, dan menyapihnya dalam usia dua tahun. Bersyukurlah kepada-ku dan kedua orang tuamu. Hanya kepada Aku kembalimu”. (Fauzi, 2020)

Penafsiran dari ayat diatas seorang ayah harus memperhatikan pendidikan seorang anak, dalam hal mendidik anak yang baik bagaimana, dan mentaati perintah orang tuanya selama bukan termasuk perbuatan atau hal yang dilarang oleh Allah, ini menunjukkan adanya nilai-nilai pendidikan islam pada ayat tersebut (Nufus, 2017).

\section{Nilai-nilai pendidikan islam dalam Hadist}

Telah kita bahas sebelumnya bahwa kebenaran nilai-nilai pendidikan islam yang terdapat pada AlQur'an dan Hadist sebagaimna kita tahu bahwa Al-Qur'an dan Hadist merupakan dasar dari ajaran serta pendidikan yang mutlak,maka sudah seharusnya semua ajaran yang telah di ajarkan dari dua dasar pendidikan tersebut haruslah dilaksanakan serta apabila mungkin bertentangan maka haruslah kita meninggalkannya, nilai-nilai pendidikan islam ini bisa kita mulai di bangku pendidikan (sekolah) dengan tetap berpedoman pada dasar pedoman umat islam yaitu Al-Qur'an dan hadist dengan tujuan membangun sikap religius para peserta didik ${ }^{25}$

Hadist merupakan perkataan atau sabda Nabi Muhammad yang kedudukannya memiliki nilai setelah Al-Qur'an, banyak ayat yang telah menjelaskan tentang kedudukan Nabi sebagai Rasulnya ${ }^{26}$, maka Jejak Rasul inilah yang sangat berpengaruh kepada pembentukan karakter serta kepribadian seorang muslim terutama peserta $\operatorname{didik}^{27}$

\section{Hadist Nabi yang berisi tentang Nilai-nilai pendidikan islam}

Beberapa hadist memuat prinsip pendidikan, seperti beberapa prinsip dasar tentang pedoman menyampaikan suatu ilmu juga tentang prinsip dasar mencari ilmu,seperti yang di contohkan hadis yang memiliki arti sebagai berikut: "Barang siapa mempelajari suatu ilmu yang tidak untuk mencari keridhaan Allah,tetapi hanya untuk mendapatkan nilai-nilai material dari kehidupan duniawi, maka ia tidak akan mencium bau syurga." Riwayat Ahmad, Abu Dawud, dan ibnu Majah ${ }^{28}$

Dalam sebuah konteks jika dilihat pendidikan pada saat ini lebih memperlihatkan sudah berkurangnya sikap-sikap positif anak, oleh karena itu sangat diperlukan bimbingan-bimbingan khusus dalam pembentukan sikap sopan santun anak,nilai-nilai sikap ini sudah pasti ada dalam kandungan Al-

\footnotetext{
${ }^{25}$ Benny Prasetya, "9 Pengembangan Budaya Religius Di Sekolah,” Jurnal Edukasi 2, no. 1 (2014).

${ }^{26}$ Fitri, "Pendidikan Karakter Prespektif Al-Quran Hadits."

27 Kholidah, "Pola Integrasi Nilai-Nilai Keislaman Dalam Pembelajaran Pendidikan Agama Islam Pada Lembaga Pendidikan.”

${ }^{28}$ Rizal, "Nilai-Nilai Pendidikan Islam Yang Terkandung Dalam Alquran Surat As-Sajdah Ayat 9 Relevansinya Dengan Pendidikan Pranatal."
} 
Qur'an dan Hadist Nabi, adapun sikap-sikap yang perlu di perbaiki saat ini nilai sopan santun yang semakin menurun, sikap hormat kepada orang yang lebih tua semakin berkurang ${ }^{29}$.

Oleh sebab itu dengan peran serta orang tua dalam pemberian pendidikan bimbingan moral dan budi pekerti yang luhur,merupakan suatu upaya demi membentuk karakter anak yang baik Jika kita lihat dari tinjauan hadist, disana ada hadist-hadist yang menjelaskan tentang hal terkait,sertabbisa kita jadikan dasar untuk pembangunan karakter yang baik untuk anak, berikut salah satu contoh hadist yang menunjukkan proses pembangunan karakter anak ${ }^{30}$.

Maksud dari Hadist ini memberikan pengertian bahwa dalam pembentukan karakter anak haruslah sesui dengan tahapan-tahapan, seperti saat anak masih pada usia kanak-kanak, maupun saat masih dalam masa pembentukan janin dalam kandungan. Selanjutnya yang merupakan tujuan akhir sebuah pendidikan karakter anak ialah pembentukan kapribadian anak agar memiliki akhlakul karimah seperti Akhlaq RasulullahbSAW. Karena dengan adanya pendidikan karakter yang bercermin pada sifat serta Akhlakn Rasul, dengan demikian generasi penerus akan menjadi generasi yang membanggakan.

Seperti hadist telah diriwayatkan Bukhori muslim, yang memiliki arti sebagai berikut :“ Sesungguhnya Aku(Muhammad) di utus ke muka bumi ini untuk menyempurnakan Akhlak manusia (H.R muslim)

Dengan berbagai metode pendidikan karakter serta petunjuk-petunjuk yang berasal dari AlQur'an serta Hadist kemungkinan akan munculnya karakter anak yang bermasalah sangatlah kecil, masalah-masalah yang dimaksud diantaranya : anak yang susah diatur serta sulit untuk di ajak untuk bekerja sama, kurangnya sikap terbuka kepada orang tua, tidak menanggapi secara positif terhadap bermacam-macam, sulit dalam bersosialisasi dengan teman, tidakbisa menerima yang terjadi serta beranggapan bahwa dirinya dan hidupnya hanya sebagai bahan olok-olokan(bahan tertawaan. Malah yang muncul ialah sebaliknya, manusi yang memiliki budi pekerti yang luhur, manusi yang peduli terhadap lingkungan serta bisa membentuk perubahan yang positif bagi umat manusia

Al-Qur'an dan hadist merupakan pentunjuk terbaik bagi umat islam didalamnya berisi segala petunjuk bagi kehidupan manusia dimana petunjuk-petunjuk tersebut merupakan petunjuk yang terbaik untuk manusia agar lebih dekat kepada penciptanya Allah SWT disini. Disini AL-Qur'an menduduki urutan paling utama dan Hadist berada urutan kedua dalam pengambilan sumber-sumber sebagai pedoman untuk manusia termasuk sebagai pedoman untuk pendidikan atau dasar pendidikan bagi penuntun umat manusia

\footnotetext{
${ }^{29}$ M Basori Alwi, "Etika Pendidik Dan Peserta Didik Dalam Perspektif Al Ghozali Dan Ibn Miskawaih," Attaqwa: Jurnal Ilmu Pendidikan Islam 17, no. September (2021): 152-63.

30 Suharnis, "Nilai-Nilai Pendidikan Islam Dalam Keluarga."

29| Falasifa, Vol. 12 Nomor 2 September 2021
} 
Ike Septianti

Devy Habibi Mubammad

Ari Susandi

Dalam Al-Qur'an terdapat beberapa surat yang didalammya ada nilai-nilai tentang pendidikan agama islam diantaranya yaitu surat al hujurat dan surat Luqman, pada kedua surat tersebut terdapat kandungan yang sedikit berbeda namun dalam artian yang sama yaitu sama-sama membahas tentang pendidikan.

Kandungan surah luqman lebih lepada peran serta orang tua terhadap pendidikan anaknya, serta surah luqman juga menjelaskan tentang pentingnya bersikap baik terhadap kedua orang tuanya

Bukan hanya pada Al-Qur'an nilai-nilai pendidikan juga terdapat pada Hadist, Beberapa hadist memuat prinsip pendidikan, seperti beberapa prinsip dasar tentang pedoman menyampaikan suatu ilmu juga tentang prinsip dasar mencari ilmu,seperti beberapa hadist yang berisi tentang nilai-nilai pendidkan seperti berikut :

"Barang siapa mempelajari suatu ilmu yang tidak untuk mencari keridhaan Allah,tetapi hanya untuk mendapatkan nilai-nilai material dari kehidupan duniawi, maka ia tidak akan mencium bau syurga." Riwayat Ahmad, Abu Dawud, dan ibnu Majah ${ }^{31}$

Dari penjelasan diatas dapat diambil beberapa metode atau cara dalam mendidik seorang anak didik khususnya dalam pendidikan karakter yang itu seua bersumber dari Al-Qur'an dan Hadist. Sehingga kemungkinan munculnya karakter yang tidak baik atau bermasalah pada diri anak-anak didik sangatlah kecil.

\section{KESIMPULAN}

Sumber pokok yang dijadikan oleh manusia sebagai dasar kehidupannya. Dan mengandung nilai-nilai pendidikan di dalamnya yaitu al-Qur'an dan Hadist. Dimana didalam al-qur'an dan hadist berisi tentang tuntunan, ajaran serta metode tentang pendidikan, terkhusus pendidikan agama Islam.

Didalam al-Qur'an dan Hadist terdapat nilai-nilai pendidikan yang merupakan dasar untuk insan serta memiliki kedudukan yang paling utama sebagai sumber dalam pembentukan manusia, yang mana pendidikan tersebut merupakan suatu upaya menjadikan manusia yang berakhlaqul karimah, dan mampu menjadi insan yang lebih taat, taqwa serta selalu mendekatkan dirinya kepada Allah SWT.

Di dalam Al-Qur'an, nilai-nilai pendidikan islam terdapat pada surah Al-Hujurat ayat 11 dan ayat 12, dan juga terdapat pada surah Luqman ayat 13 dan ayat 14, dimana isi dari surah Hujurat Ayat 11-12 lebih kepada nilai-nilai pendidikan etika dan pendidikan karakter. Pada etika dan karakter disini lebih kepada bagaimana cara kita ber kita bersosialisasi dengan seseorang, sikap sopan santun dalam kehidupan bermasyarakat. Sedangkan pada ayat 13 dan 14 dari surat Luqman lebih kepada orang

31 Kholidah, "Pola Integrasi Nilai-Nilai Keislaman Dalam Pembelajaran Pendidikan Agama Islam Pada Lembaga Pendidikan." 
tuanya, bagaiamna mereka selaku orang tua dalam mendidik anak-anaknya. Kedua surat tersebut merupakan contoh dari beberapa surat yang berisi tentang nilai-nilai pendidikan islam.

\section{DAFTAR PUSTAKA}

Akmansyah, M. “Al-485 \$1 Dan Al-Sunnah Sebagai Dasar Ideal Pendidikan Islam.” Jurnal Pengembangan Masyarakat Islam 8, No. 2 (2010): 127-42.

Alwi, M Basori. "Etika Pendidik Dan Peserta Didik Dalam Perspektif Al Ghozali Dan Ibn Miskawaih.” Attaqwa: Jurnal Ilmu Pendidikan Islam 17, No. September (2021): 152-63.

Dian Permana, Hisam Ahyani. "Implementasi Pendidikan Islam Dan Pendidikan Multikultural Pada Peserta Didik." Dian Permana, Hisam Abyani Jurnal Tawadhu 4, No. 1 (2020): 1689-99.

Fida, Imanuddin Abil. "Liberalisme Dalam Pendidikan Islam Di Perguruan Tinggi." Journal Of Islamic Education I, No. 1 (2016): 56-70.

Fitri, Anggi. "Pendidikan Karakter Prespektif Al-Quran Hadits." Ta'lim: Jurnal Studi Pendidikan Islam Vol.1 No.2, No. 2 (2018): 38-67.

Frimayanti, Ade Imelda. "Implementasi Pendidikan Nilai Dalam Pendidikan Agama Islam." AlTadzkizyyah: Jurnal Pendidikan Islam 8, No. 2 (2017): 240.

Harimulyo, Muhammad Syamsi, Benny Prasetiya, And Devy Habibi Muhammad. "Nilai-Nilai Pendidikan Akhlak Dalam Kitab Risalatul Mu'awanah Dan Relevansinya.” Jurnal Penelitian Ipteks 6, No. 1 (2021): 72-89. Https://Doi.Org/10.32528/Ipteks.V6i1.5253.

Hidayah, Ulil. “Rekonstruksi Evaluasi Pendidikan Moral Menuju Harmoni Sosial.” Jurnal Pedagogik 05, No.

Https://Ejournal.Unuja.Ac.Id/Index.Php/Pedagogik\%0apermata_Ulya@Yahoo.Co.Id.

Kholidah, Lilik Nur. "Pola Integrasi Nilai-Nilai Keislaman Dalam Pembelajaran Pendidikan Agama Islam Pada Lembaga Pendidikan.” At-Ta'dib 10, No. 2 (2015): 325-40.

Muhammad, Devy Habibi. "Implementasi Pendidikan Humanisme Religiusitas Dalam.” Edumaspul Jurnal Pendidikan 4, No. 2 (2020): 122-31.

Muniroh, Alimul. "Implementasi Nilai-Nilai Pendidikan Islam Dalam Surah As-Saffat Ayat 102." Darajat: Jurnal Pendidikan Agama Islam 1, No. 1 (2018): 1-15.

Prasetya, Benny. “9 Pengembangan Budaya Religius Di Sekolah.” Jurnal Edukasi 2, No. 1 (2014).

Rangkuti, Suheri Sahputra. "Suheri Sahputra Rangkuti : Nilai-Nilai Pendidikan Islam Dalam Tafsir Ayat Jihad ..." Jurnal Kependidikan Islam 4, No. 2 (2018): 184-201.

Rizal, Soni Samsu. "Nilai-Nilai Pendidikan Islam Yang Terkandung Dalam Alquran Surat As-Sajdah Ayat 9 Relevansinya Dengan Pendidikan Pranatal." Tarbiyah Al-Aulad 1, No. 2 (2016): 16.

31| Falasifa, Vol. 12 Nomor 2 September 2021 
Ike Septianti

Devy Habibi Mubammad

Ari Susandi

Siti Ngaisah. "Nilai-Nilai Pendidikan Akhlak Dalam Surat ( Kajian Tafsir Al-Mishbah Karya Prof . Dr . M . Quraish Shihab ) Program Studi Pendidikan Agama Islam Institut Agama Islam Negeri” 13 (2018).

Soekmawati, Indah. "Nilai-Nilai Penting Pendidikan Islam Berbasis Al Quran Dan Sirah Nabi Dalam Peningkatan Kualitas Pengajaran." Jurnal Kependidikan 7, No. 2 (2019): 204-14. Https://Doi.Org/10.24090/Jk.V7i2.3032.

Suharnis. "Nilai-Nilai Pendidikan Islam Dalam Keluarga.” Musawa 7, No. 1 (2015): 52-79.

Susandi, Ari. "Pendidikan Life Skills Dalam Penanaman Nilai-Nilai Agama Islam Di Sekolah Dasar." Al-Insyirob: Jurnal Studi Keislaman 6, No. 2 (2020): 95-111. Https://Doi.Org/10.35309/Alinsyiroh.V6i2.3867.

Syakhrani, Abdul Wahab. "Memperkuat Eksistensi Pendidikan Islam Di Era 4.0.” Cbjis: Cross-Border Journal Of Islamic Studies 1, No. 2 (2019): 57-69. Https://Doi.Org/10.37567/Siln.V1i2.90.

Zulkarnain, S, And Kementerian Pemuda. "Pendidikan Karakter Dalam Al-Quran Surat Al-Hujurat" Ix, No. 2 (2016): 133-45. 